\title{
ПАТЕНТНАЯ АКТИВНОСТЬ НЕФТЕГАЗОВЫХ КОМПАНИЙ КАК ОСНОВА ИННОВАЦИОННОГО РАЗВИТИЯ В СФЕРЕ СПГ-ТЕХНОЛОГИЙ
}

\author{
(c) 2021 Шепелев Роман Евгеньевич \\ стажер-кандидат, \\ Кафедра экономики и управления предприятиями и производственными комплексами \\ Санкт-Петербургский государственный экономический университет, Россия, Санкт-Петербург \\ E-mail: shepelevroman@gmail.com
}

В статье предложены методы патентной аналитики для оценки уровня инновационного развития нефтегазовых и промышленных компаний в области развития СПГ-технологий На примере компаний выполнена оценка патентного портфеля крупнейших отечественных и зарубежных компаний в области СПГ-технологий. Построены патентные ландшафты по основным направлениям развития технологий в области СПГ.

Ключевые слова: патентная информация, патентный ландшафт, патентная аналитика, СПГ, инновационная деятельность, нефтегазовые компании, конкурентоспособность.

Согласно прогнозу British Petroleum [11] потребление природного газа в ближайшие десятилетия будет расти, при этом будет возрастать и роль СПГ в будущем энергетическом балансе мира. Предполагается, что спрос на СПГ к 2040 году увеличится до 790 млн. т., а «доля СПГ в мировой торговле газом увеличится с 35\% в 2017 году до 52\% к 2035 году» [1]. Тем самым будущий спрос на СПГ диктует необходимость ускоренного создания мощностей по его производству.

В целях расширения присутствия на мировом рынке сжиженного природного газа, в России планируется значительно нарастить производственные мощности по сжижению газа, реализовав ряд крупных проектов, ориентированных на экспорт, информация о которых представлена в таблице 1.

Кроме того, в целях газификации и энергообеспечения субъектов Российской Федерации председатель правительства Российской Федерации М.В.Мишустин в августе 2020 года поручил Минвостокразвития РФ, Минэкономразвития России, ПАО «Газпром» и ПАО «Новатэк» разработать долгосрочную программу развития производства сжиженного природного газа в Российской Федерации [5].

Комплексный подход к решению задачи реализации проектов по производству СПГ будет носить для страны синергетический эффект, способствовать развитию смежных отраслей промышленности, в том числе за счет развития технологий в области производства криогенного оборудования, новых конструкционных и строи- тельных материалов, судостроения. Кроме того, развитие собственных технологий, внедрение инноваций позволяют снизить зависимость от иностранных разработок, получить дополнительный источник доходов от коммерциализации результатов научной деятельности.

Для эффективного управления инновационными процессами необходимо наличие достоверной и исчерпывающей базы научнотехнической информации, которой является патентная информация. Уделяя внимание качественному отбору патентной информации, компания получает преимущества перед конкурентами, в т.ч. возможность завоевания рынка за счет использования исключительных прав на изобретения [6]. В целях анализа тенденций разработки техники и технологий обычно применяют патентные исследования, на основании которых формируются патентные ландшафты, применяемые для визуализации патентной информации. В состав патентного ландшафта входят различные аналитические представления, в том числе тренды, области интенсивного патентования, области высокой технологической конкуренции, открытые патентные сегменты [7].

Целью настоящего исследования является анализ уровня технологического развития компаний (на основании анализа патентной информации), участвующих в реализации проектов по производству СПГ. Для анализа были отобраны нефтегазовые компании (ПАО «Газпром, ПАО «Роснефть», ПАО «Новатэк», Shell, Total, China national petroleum company (далее - CNPC) и 
Таблица 1. Информация о существующих и планируемых к созданию объектов производства СПГ в РФ

\begin{tabular}{|c|c|c|c|c|}
\hline Новые проекты & Участники проекта & Ресурсная база & $\begin{array}{l}\text { Проектная } \\
\text { мощность, } \\
\text { млн. т/год }\end{array}$ & $\begin{array}{c}\text { Год начала } \\
\text { поставок }\end{array}$ \\
\hline \multicolumn{5}{|c|}{ Действующие объекты } \\
\hline $\begin{array}{l}\text { Сахалин-2 } \\
(1-2 \text { линии })\end{array}$ & $\begin{array}{l}\text { ПАО «Газпром», } \\
\text { Shell, Mitsui, Mitsubishi }\end{array}$ & $\begin{array}{l}\text { Месторождения шельфа } \\
\text { о. Сахалин }\end{array}$ & 9,6 & 2009 \\
\hline Ямал СПГ & $\begin{array}{l}\text { ПАО «Новатэк», Total, } \\
\text { CNPC }\end{array}$ & $\begin{array}{l}\text { Южно-Тамбейское ме- } \\
\text { сторождение }\end{array}$ & 16,5 & 2017 \\
\hline \multicolumn{5}{|c|}{ Перспективные объекты } \\
\hline $\begin{array}{l}\text { Сахалин-2 } \\
\text { (3 линия) }\end{array}$ & $\begin{array}{l}\text { ПАО «Газпром», } \\
\text { Shell, Mitsui, Mitsubishi }\end{array}$ & $\begin{array}{l}\text { Месторождения шельфа } \\
\text { о. Сахалин }\end{array}$ & 5,4 & $2023-2024$ \\
\hline Арктик СПГ-2 & $\begin{array}{l}\text { ПАО «Новатэк», Total, } \\
\text { CNPC, Mitsui }\end{array}$ & $\begin{array}{l}\text { Утреннее месторожде- } \\
\text { ние }\end{array}$ & 19.8 & 2022 \\
\hline $\begin{array}{l}\text { Балтийский СПГ } \\
\text { (Комплекс по переработ- } \\
\text { ке этансодержащего газа } \\
\text { и производству СПГ в } \\
\text { районе г. Усть-Луга) }\end{array}$ & $\begin{array}{l}\text { ПАО «Газпром», } \\
\text { АО «РусГаз } \\
\text { Добыча», ООО «Русхим } \\
\text { альянс», } \\
\text { Linde (в качестве лицен- } \\
\text { зиара технологии) }\end{array}$ & $\begin{array}{l}\text { Ачимовские и валан- } \\
\text { жинские залежи место- } \\
\text { рождений Надым-Пур- } \\
\text { Тазовского региона }\end{array}$ & 13,0 & 2024-2027 \\
\hline Восток Ойл & $\begin{array}{l}\text { Роснефть, } \\
\text { (перечень участников } \\
\text { формируется) }\end{array}$ & $\begin{array}{l}\text { Западно-Иркинский уча- } \\
\text { сток и месторождения } \\
\text { Ванкорского кластера }\end{array}$ & $30-50$ & $2024-2030$ \\
\hline КСПГ Портовая & $\begin{array}{l}\text { ПАО «Газпром», } \\
\text { Linde (в качестве лицен- } \\
\text { зиара технологии) }\end{array}$ & ЕСГ РФ & до 1,5 & 2021 \\
\hline
\end{tabular}

Источник: Составлено автором по данным $[2,3,4]$

производители оборудования для производства, транспортировки и хранения СПГ, в т.ч. лицензиары технологий (Mitsui, Linde, Mitsubishi Heavy Industries, Huindai Heavy Industries) (табл. 2).

При выполнении патентного поиска использовались открытые базы данных, а именно международные базы данных Espacenet (свыше 120 миллионов патентных документов) и WIPO (свыше 93 миллионов патентных документов). Как было отмечено в статье [8] «существует погрешность, выдаваемая при анализе патентной информации. Это связано с тем, что передача данных национальными патентными ведомствами осуществляется на договорной основе, вследствие чего некоторые государства не успевают предоставить полную информацию, а также тем, что в отдельных компаниях патентообладателем указывается дочернее предприятие, в наименовании которого не содержится название головной компании».

Используя информацию вышеупомянутых баз данных получена информация о распределении общего числа патентов компаний, полученных во всех сферах деятельности компаний за пятилетний период с 2016 по 2020 гг. (табл. 2).

Лидером по общему количеству полученных патентов за пять лет является японская компания Mitsui, которая за 5-ти летний период зарегистрировала свыше 6 тыс. патентов, что может говорить о Японии, как об одной из ведущих индустриальных стран мира. В тройку лидеров также входит японская Mitsubishi Heavy Industries и южнокорейская Huindai Heavy Industries (свыше 6 тыс. и 3,5 тыс. патентов соответственно). При этом, необходимо отметить, что все три вышеперечисленные компании являются многопрофильными промышленными компаниями, занимающимися разработкой и производством оборудования самого широкого спектра.

Чтобы оценить активность патентования компаний в области развития СПГ-технологий, необходимо проследить динамику ежегодного прироста патентов с 2016 по 2020 гг. по индексам МПК, относящимся к деятельности компаний в указанной области. При выполнении поиска патентов, относящихся к области СПГ были использованы следующие индексы МПК:

В63В - Корабли или прочие плавучие суда; оборудование для судов;

F25J1 - Способы и устройства для сжижения или отверждения газов или их смесей;

F17C - Сосуды для помещения или хранения газов в сжатом, сжиженном или твердом состо- 
Таблица 2. Динамика прироста патентов нефтегазовых компаний с 2016 по 2020 гг. (кол-во патентов в шт.)

\begin{tabular}{|c|l|c|c|c|c|c|c|}
\hline № & \multicolumn{1}{|c|}{ Название компании } & 2016 & 2017 & 2018 & 2019 & 2020 & Итого \\
\hline 1. & Mitsui & 1305 & 1284 & 1382 & 1524 & 1247 & 6742 \\
\hline 2. & Mitsubishi Heavy Industries & 1137 & 1035 & 797 & 2208 & 1186 & 6363 \\
\hline 3. & Huindai Heavy Industries & 1181 & 626 & 1287 & 252 & 184 & 3530 \\
\hline 4. & Royal Dutch Shell & 864 & 941 & 695 & 482 & 356 & 3338 \\
\hline 5. & Linde & 873 & 950 & 739 & 521 & 195 & 3278 \\
\hline 6. & Total & 316 & 331 & 308 & 312 & 322 & 1589 \\
\hline 7. & СNРС & 46 & 63 & 261 & 356 & 649 & 1375 \\
\hline 8. & ПАО «Газпром» & 167 & 194 & 208 & 191 & 201 & 961 \\
\hline 9. & ПАО «Роснефть» & 35 & 32 & 38 & 15 & 35 & 155 \\
\hline 10. & ПАО «НоватэК» & 0 & 2 & 3 & 0 & 1 & 6 \\
\hline
\end{tabular}

Источник: Составлено автором по данным $[9,10]$

янии; газгольдеры постоянной емкости; наполнение сосудов газами в сжатом, сжиженном или твердом состоянии или выпуск их из сосудов.

Выполнив анализ патентов по вышеуказанным индексам, получим сводную таблицу патентной активности компаний (табл.3).

Абсолютным лидером по числу патентов в области СПГ-технологий за 2016-2020 гг. является японская компания Mitsubishi Heavy (334 патентов). За ней следуют Linde и Mitsui (331 и 306 патентов соответственно). При этом, ни одна компания не показывает динамику постоянного роста либо уменьшения количества патентов со временем.

Оценить, насколько компании заинтересованы развития технология в области СПГ, можно с помощью подсчета коэффициента отношения количества патентов в области СПГ к общему числу патентов компании (рис. 1).

Полученные результаты демонстрируют лидерство Linde в области развития СПГ-техно- логий, каждое десятое патентуемое компанией техническое решение относится к области СПГ. Показатели ПАО «Новатэк» не являются репрезентативными, т.к. общее число патентов и патентов в области СПГ меньше 10 штук. Делать выводы на основании такой незначительной выборке нельзя. Стоит отметить, что у ПАО «Газпром» доля патентов в области СПГ больше чем у французской компании Total, одного из лидеров этой отрасли. В настоящее время Total является вторым по величине частным производителем СПГ с 10\% мирового рынка. Этот факт подтверждает, что ПАО «Газпром» принимает активное участие в проектах по расширению производства и использования СПГ, а также вкладывает значительные средства в развитие собственных технологий.

Для разностороннего анализа целесообразно выполнить распределение данных о полученных патентах по вышеуказанным индексам МПК (рис. 2).

Таблица 3. Общая патентная активность компаний в области СПГ-технологий в период с 2016 по 2020 гг. (кол-во патентов в шт.)

\begin{tabular}{|c|l|c|c|c|c|c|c|}
\hline № & \multicolumn{1}{|c|}{ Название компании } & 2016 & 2017 & 2018 & 2019 & 2020 & Итого \\
\hline 1. & Mitsubishi Неavy Industries & 83 & 55 & 71 & 81 & 44 & 334 \\
\hline 2. & Linde & 78 & 96 & 84 & 41 & 32 & 331 \\
\hline 3. & Mitsui & 42 & 63 & 82 & 95 & 24 & 306 \\
\hline 4. & Huindai Heavy Industries & 13 & 13 & 17 & 46 & 6 & 95 \\
\hline 5. & Royal Dutch Shell & 25 & 27 & 11 & 18 & 14 & 95 \\
\hline 6. & Total & 6 & 0 & 0 & 2 & 6 & 14 \\
\hline 7. & ПАО «Газпром» & 2 & 1 & 4 & 1 & 2 & 10 \\
\hline 8. & ПАО «Новатэк» & 0 & 0 & 0 & 2 & 2 & 4 \\
\hline 9. & СКРС & 0 & 0 & 0 & 0 & 1 & 1 \\
\hline 10. & ПАО «Роснефть» & & 0 & 1 & 0 & 0 & 2 \\
\hline
\end{tabular}

Источник: Составлено автором по данным $[9,10]$ 


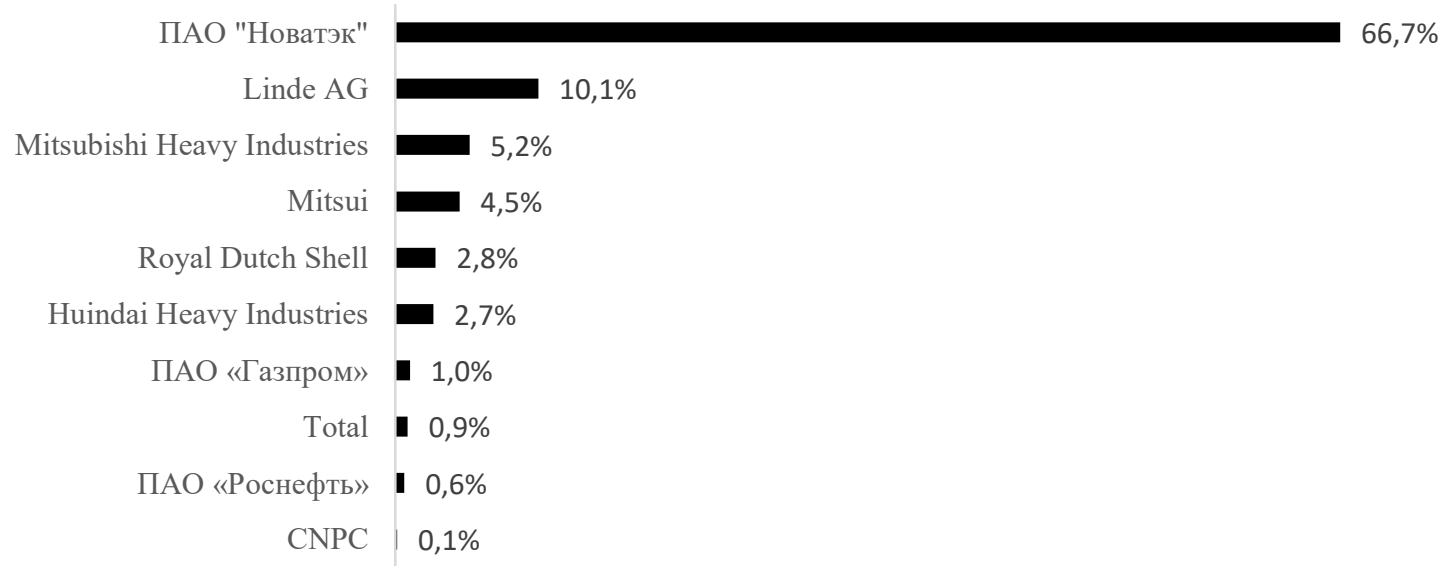

Puc. 1. Отношение количества патентов в области развития СПГ-технологий к общему числу патентов компаний,\%

Индекс МПК В63В:

Корабли или прочие плавучие суда; оборудование для судов

Индекс МПК F25J1:

Способы и устройства для

сжижения или отверждения

газов или их смесей

Linde

244

238

Huindai Heavy Ind

Royal Dutch Shell

Total 7

ПАО "Газпром" । 3

CNPC | 2

ПАО "Роснефть"
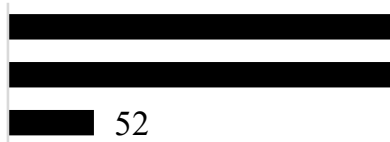

39

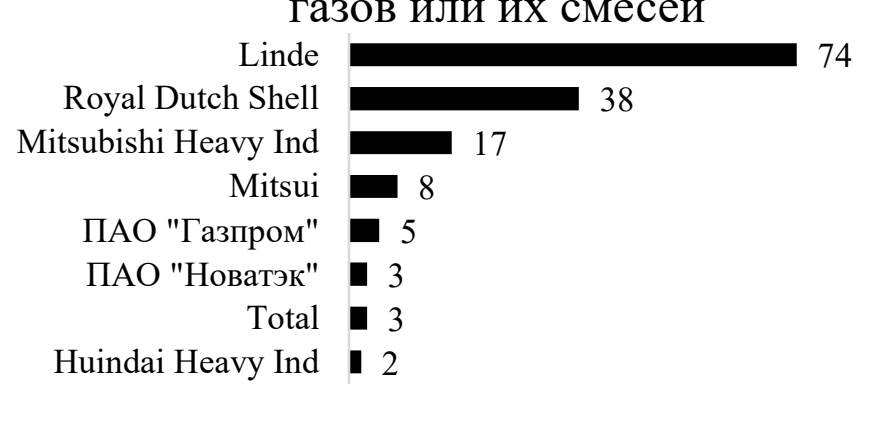

Индекс МПК F17C: Сосуды для помещения или хранения
газов в сжатом, сжиженном или твердом состоянии, газгольдеры

Linde

Mitsubishi Heavy Ind

Mitsui

Huindai Heavy Ind

Royal Dutch Shell

Total 4

ПАО "Газпром" | 2

ПАО "Новатэк" । 1

Puc. 2. Распределение количества патентов компаний по индексам МПК за 2016-2020 гг., шт. 
Компания Linde лидирует по количеству патентов в области разработки технологий производства и хранения СПГ (индексы МПК - F25J1 и F17C), это объясняется тем, что Linde является одной из крупнейших химических компаний мира. Компания является глобальным лидером на мировом рынке газов, а именно технических и медицинских газов для различных отраслей промышленности, включая производство стали и химическое обогащение, пищевую промышленность и производство стекла.

Патентные ландшафты, представленные в данной статье, подтверждают, что стратегию развития компании в области развития СПГ строят исходя из результатов отбора патентной информации, т.к. любое новое техническое решение требует изучения опыта предшественников и конкурентов.

На основании анализа патентов в области развития СПГ-технологий выделены дополнительные технологические тренды у между- народных нефтегазовых компаний и крупных игроков рынка:

- повышение эффективности существующих технологий производства и хранения СПГ. Компании продолжают разрабатывать технологии для повышения эффективности текущих производственных линий, улучшая конструкцию оборудования и оптимизируя процессы, что связано с ростом использования газа в качестве топлива;

- создание мобильных заводов производства СПГ, в т.ч. собственного флота газовозов. Нефтегазовые компании совместно с промышленными компаниями разрабатывают плавучие заводы по сжижению газа для обеспечения доступа к инфраструктуре шельфовых и небольших морских месторождений. Также компании разрабатывают плавучие терминалы для регазификации СПГ. Для использования потенциала ресурсов на суше разрабатываются мобильные модульные установки для производства СПГ.

\section{Библиографический список}

1. СПГ обгонит трубопроводный газ в мировой торговле к 2035 году и займет $52 \%$ рынка. [Электронный реcypc] - URL: https://tass.ru/ekonomika/9687375 (дата обращения: 01.02.2021).

2. Проблемы и перспективы СПГ-проектов. [Электронный ресурс].- URL: https://www.pwc.ru/ru/oil-and-gas/ assets/challenges-and-outlook-for-lng-projects-rus.pdf (дата обращения: 01.02.2021).

3. Официальный сайт ПАО «Новатэк». [Электронный ресурc]. - URL: https://www.novatek.ru (дата обращения: 01.02.2021).

4. Новак анонсировал строительство более десяти СПГ-заводов в России. [Электронный ресypc]. - URL: https:// www.rbc.ru/business/02/02/2021/ 601917309a79470e4a3878e6 (дата обращения: 01.02.2021).

5. Мишустин поручил Минпромторгу к ноябрю разработать меры поддержки выпуска СПГ-оборудования [Электронный ресурс].—URL: https://tass.ru/ekonomika/9330933 (дата обращения: 01.02.2021).

6. Р. Е.Шепелев, В.Н. Сорокин Возможности патентной информации для повышения конкурентоспособности компаний // «Промышленный сервис» - 2016, - № 2 (59).

7. Ена O.B., Попов Н.В. Методология разработки патентных ландшафтов Проектного офиса ФИПС [Электронный ресурс].- URL: https://rupto.ru/ru/news/metodologiya-razrabotki-patentnyh-landshaftov-proektnogoofisa-fips (дата обращения: 01.02.2021).

8. Волков А.Т., Шепелев Р. Е. Современное состояние нефтегазовой отрасли - источника спроса инноваций// «Вестник университета» -2019 , № 6, с.68-76.

9. База данных Espacenet [Электронный ресурс].- URL: https://www.epo.org/searching-for-patents/technical/ espacenet.html (дата обращения 01.02.2021).

10. База данных WIPO [Электронный ресурс]. - URL: https://www.wipo.int/portal/en/index.html (дата обращения 01.02.2021).

11. Аналитический отчет British Petroleum. Energy Outlook 2020. [Электронный pecypc].- URL: https://www. bp.com/content/dam/bp/business-sites/en/global/corporate/pdfs/energy-economics/energy-outlook/bp-energyoutlook-2020.pdf (дата обращения: 01.02.2021). 